Niranjan Fernando, Marina Braun-Unkhoff and Uwe Riedel, "Modeling study of the entrained flow gasification of ethylene glycol, a surrogate fuel for a pyrolysis oil”, Energy \& Fuels, 33 (2019), 9818-9827.

This document is the Accepted Manuscript version of a Published Work that appeared in final form in Energy \& Fuels, copyright $\odot$ American Chemical Society after peer review and technical editing by the publisher. To access the final edited and published work see https://pubs.acs.org/doi/full/10.1021/acs.energyfuels.9b01564

https://doi.org/10.1021/acs.energyfuels.9b01564 


\title{
A modeling study of the entrained flow gasification of ethylene glycol, a surrogate fuel for a pyrolysis oil
}

\author{
Niranjan Fernando*, Marina Braun-Unkhoff, Uwe Riedel \\ Institute of Combustion Technology, German Aerospace Center (DLR) \\ Pfaffenwaldring 38-40, 70569 Stuttgart, Germany
}

\begin{abstract}
The complex composition of pyrolysis oils makes it challenging to develop detailed reaction mechanisms to model the fuel's gasification chemistry. As a solution, surrogate fuels with a few chemical components with similar behavior to pyrolysis oils in terms of fundamental combustion properties and major physical properties can be used to model the fuel's gasification chemistry. In the present work, ethylene glycol is selected as a single component surrogate for the pyrolysis oil because of its similar chemical and physical properties to pyrolysis oil. However, even with this simplification, the detailed chemical kinetic mechanism for ethylene glycol available in literature is still too large to allow its efficient use in two-dimensional simulations. Therefore, in the present work, a reduced reaction mechanism has been developed for describing the gasification chemistry of ethylene glycol. This mechanism was first validated by computing ignition delay times and laminar flame speeds of several relevant species and by comparing the calculated values against published experimental data. Overmore, the developed reduced reaction mechanism was used to perform a CFD simulation of the Research Entrained Flow Gasifier (REGA) operated at the Karlsruhe Institute of Technology (KIT). The mechanism was further validated by comparing the simulation results with published experimental data from the REGA experiments. In all validation computations, the developed reduced chemical kinetic reaction mechanism showed very good agreement with the experimental data. Also, the validated reduced reaction model was used to perform a parameter study for typical REGA conditions, by investigating its performance with respect to equivalence ratio, fuel preheat temperature, and operating pressure. From this parameter study, it has been found that both the fuel preheat temperature and the operating pressure have a marginal influence on the composition of the syngas produced. The equivalence ratio had the strongest effect on the syngas composition, with an almost linear variation in the investigated equivalence ratio range.
\end{abstract}




\section{INTRODUCTION}

Biomass gasification is a widely applied thermo-chemical conversion technology to produce syngas, starting from low grade biomass feedstock such as wood, straw or rice husk. ${ }^{1-4}$ Gasifiers come under a variety of technologies. Packed bed, fluidized bed, and entrained flow gasifiers are examples. ${ }^{2}$ The packed bed gasifiers are usually operated with woody biomass at atmospheric pressure and can be used with a variety of feedstock. The conversion can be either continuous or batch wise. ${ }^{5-6}$ Fluidized bed gasifiers require a finer feed stock with a small particle size in order to maintain a stable fluidized bed of fuel particles. They have the advantages of high heat transfer rates and uniform temperatures in the gasifier due to extensive mixing. However, extensive gas cleaning is required in order to remove the particulate matter from the produced syngas. ${ }^{7-8}$ In an entrained flow gasifier, the fuel in droplet or powder form is injected with an oxidant from the top of the gasifier into a high temperature environment. ${ }^{9}$ Due to the high temperatures in an entrained flow gasifier, the tars and liquid products become devolatilized to hydrogen and methane, yielding a tar free syngas. Entrained flow gasifiers can be operated under higher pressures $(80 \mathrm{bars})^{10}$ and this operation under higher pressures is advantageous when syngas is intended to be subjected to further high pressure conversion processes such as the FischerTropsch process. ${ }^{11}$ Even though this is a widely used process, the complex physical and chemical processes that take place inside a specific gasifier are still not well understood. Therefore, many research studies worldwide are focused on investigating various aspects of gasification processes. ${ }^{6,12-14}$ These studies can be mainly classified as experimental approaches and modelling approaches.

In the experimental approach, a series of experiments have been performed on the gasification system under different operating conditions. ${ }^{14-16}$ In the modelling approach, a suitable numerical model is developed and validated for the gasifier under consideration. ${ }^{12,}{ }^{17}$ The validated numerical model is then used to investigate the performance of the gasifier under different conditions. ${ }^{6}$

With the development of computer technology, numerical models are widely applied nowadays to study gasification processes, mainly due to their advantages over the experimental approach with respect to cost and time consumption. Also, numerical models can be used to perform detailed studies of specific parameters under high resolution.

In the numerical models of gasifiers, ${ }^{6},{ }^{18-19}$, the gasification chemistry is modeled using a chemical kinetic reaction mechanism. Commonly used mechanisms are global mechanisms with a small number of species and reactions due to their reduced CPU time requirement. However, global mechanisms have only a narrow range of applicability with respect to the operating conditions. ${ }^{20}$ Because of this, when developing models to investigate the gasification process over a range of operating parameters such as the equivalence ratio and operating pressure detailed fuel gasification chemistry should be used in the model. Developing detailed chemical kinetic reaction mechanisms for biomass based fuels such as pyrolysis oils are challenging due to their complex composition with a large number of chemical components including aldehydes, ketones, 
phenols, acids and oxygenates. ${ }^{21}$ As a solution to this, the concept of a surrogate fuel is used. A surrogate fuel is a model fuel with a simple composition that has similar chemical and physical properties to the original biomass fuel; thus, detailed mechanisms can be developed for surrogate fuels because of their well-defined composition (a few components only). For example, ethylene glycol is used as a single component surrogate to represent real biomass pyrolysis oil stemming from straw or agricultural by-products. ${ }^{22-25}$ The hetero-polymers present in these feed stock result in high oxygen content pyrolysis oil. Therefore, a high oxygen content surrogate is necessary. The oxygen present in the two hydroxyl groups in ethylene glycol serves this purpose. ${ }^{26}$ Being similar to ethanol, ethylene glycol provides an advantage in estimating the rate constants of reactions. The rate constants of analogous reactions with ethanol in the ethylene glycol mechanism can be estimated based on the ethanol rate constants. ${ }^{23}$ Also, for experimental studies, ethylene glycol has the advantages of low cost and safety. ${ }^{26}$

Even with the simplification of a surrogate fuel, the detailed mechanisms are still too large to be efficiently used in two dimensional simulations of gasification processes as a result of their large CPU time demand. Therefore, reduced reactions mechanisms are required with a fewer number of species and reactions which exhibit a similar performance to the detailed reaction mechanism in the parameter range of interest.

In this work, a reduced reaction mechanism is developed to model the gasification of pyrolysis oil using ethylene glycol as the surrogate fuel. The reduced mechanism is produced using the so called Directed Relation Graph method ${ }^{27-28}$ as implemented in the software Chemical Work Bench $(\mathrm{CWB})^{29}$ using the detailed reaction mechanism for ethylene glycol $^{26}$ as a starting point only. The reduced mechanism is thoroughly validated by computing ignition delay times and laminar flame speeds over a wide range of temperature, pressure, and equivalence ratios, and by comparing the results with published experimental data as well as with the predictions by using the detailed chemical reaction mechanism. Further, the mechanism is validated by performing Euler-Euler CFD simulations of the REGA gasifier and comparing calculated radial species profiles and temperature profiles against published experimental data. The calculated results are in very good agreement with the experimental data. The validated reduced model is then used to perform a parameter study of the REGA with respect to the fuel preheat temperature, the operating pressure, and the equivalence ratio to identify the effect of these operating conditions on the composition of the syngas produced.

\section{DEVELOPMENT OF THE REDUCED REACTION MECHANISM}

In the present work, ethylene glycol is used as a model fuel to represent a real pyrolysis oil. This selection is done based on the similarity of physical and chemical properties of ethylene glycol and biomass pyrolysis oils. For example, the mean values of density, viscosity, enthalpy of combustion and $\mathrm{C} / \mathrm{H} / \mathrm{O}$ ratio of pyrolysis oils and ethylene glycol are approximately equal. ${ }^{26}$ As mentioned in the introduction, the high oxygen content of pyrolysis oil $(30-60 \mathrm{wt} \%)^{26}$ is approximated by the two oxygen atoms in the ethylene glycol molecule (approx. 52\% wt\%). Also, the detailed chemical kinetic oxidation reaction mechanism of a single component 
surrogate is considerably simpler than that of a multi component surrogate, resulting in a lesser number of species and reactants. This is extremely important when targeting CFD simulations for a parameter study, where CPU time is a critical factor. A detailed description on the selection of ethylene glycol as a surrogate for pyrolysis oil including a comparison between properties of pyrolysis oil and ethylene glycol can be found in the study of Kathrotia et al. ${ }^{26}$ The structure of the ethylene glycol molecule is shown in Fig. 1.

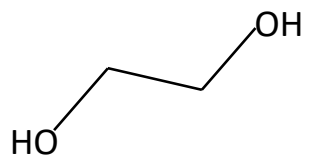

Figure 1. The chemical structure of ethylene glycol

A detailed reaction mechanism for ethylene glycol has been developed earlier in our group. This mechanism consists of 78 species and 574 reactions. ${ }^{26}$ This mechanism has been validated by using ignition delay time data of ethylene glycol in a temperature range of $800-1500 \mathrm{~K}$ at 16 bar pressure as well as using species profiles in an atmospheric flow reactor in a temperature range of $700-1200 \mathrm{~K}$ (for more details on the mechanism and validation refer to Kathrotia et al. ${ }^{26}$ ). In the present work, this validated detailed reaction model is used as the starting point to produce the reduced mechanism for ethylene glycol. Several reduced ${ }^{19,24,30-31}$ and global mechanisms ${ }^{18}$ for ethylene glycol oxidation have been used in literature. The reduced mechanism as developed within the present work has three major advantages: (i) it takes into account of the recirculation of syngas in the gasifier because of the specific reduction targets selected; (ii) it is validated over a wide range of operating conditions to ensure its applicability for parameter studies of REGA gasifier; and (iii) it is a compact one with keeping the reliability when compared to the detailed reaction mechanism.

The aim of the reduction procedure is to remove species and reactions that are unnecessary for the target(s) performance range of the reduced mechanism and thus, producing a handy mechanism, with less species and reactions, which allows its efficient use in two dimensional numerical simulations. In the present work, the reduced reaction mechanism is developed using the mechanism reduction technique called Directed Relation Graph (DRG) $)^{27-28}$ as implemented in the software Chemical Work Bench $(\mathrm{CWB}){ }^{29}$

The DRG method defines the importance index $\left(I_{A B}\right)$, which describes the importance of species $\mathrm{B}$ on the production of species $\mathrm{A}$ in the mechanism as: ${ }^{27-28}$

$I_{A B}=\frac{\sum_{i=1}^{R}\left|v_{A k} r_{k}\right| \delta_{B, k}}{\sum_{i=1}^{R}\left|v_{A k} r_{k}\right|}$

where $\mathrm{R}$ is the number of reactions in the mechanism and $\delta_{B, k}$ is equal to one if the reaction $\mathrm{k}$ contains the species B and zero otherwise. 
The protocol of the DRG mechanism reduction technique is presented in Fig. 2. The reduction starts with an initial set $(\Omega)$ of $\mathrm{n}$ important species A (in the present work, ethylene glycol, hydrogen and nitrogen) to be included in the reduced mechanism. Then, for each of the other species B in the detailed mechanism, the reaction importance index $I_{A B}$ is evaluated for all $A \epsilon \Omega$. The reaction importance index quantifies the importance of species $\mathrm{B}$ for the production rate of species A by identifying the fraction of production of A through reactions containing species B out of all reactions producing species A, as given by Eq. 1. For each B, this produces a list of importance index values for those species included within $\Omega$. If their maximum value is greater than a certain threshold, species B is added to $\Omega$, and the procedure is repeated with the updated set of $\Omega$. This procedure is repeated until no further species are added to $\Omega$; this will be the final iteration. The reduced mechanism consists of all the species included in $\Omega$ and their reactions after the final iteration. After each step within the reduction iteration, the selected characteristic quantities, here laminar flame speed and ignition delay times, are evaluated using the current version of the reduced mechanism for the target conditions (Table 1). These calculated values obtained from the current version of the reduced model are then compared against values obtained from the detailed mechanism. If the difference is below than a user given threshold, a next stage of reduction iterations is performed. This procedure is repeated until the values obtained from calculations with the reduced mechanism exceed the user given error tolerance for the target calculations. The smallest mechanism that satisfies the threshold criteria is the final reduced mechanism. ${ }^{28}$

The targets used in the reduction procedure are ignition delay times and laminar flame speed of ethylene glycol as the main fuel, as well as hydrogen species profiles (Table 1); the target conditions used are atmospheric pressure, temperature points of $298 \mathrm{~K}, 1100 \mathrm{~K}, 1500 \mathrm{~K}$, and $2000 \mathrm{~K}$ and an equivalence ratio of one. In the REGA simulations, the species hydrogen is important for two reasons: it is a major component in the syngas and also because the recirculation flow in the gasifier ${ }^{25}$ brings syngas to the fuel injection zone of the reactor where it is mixed and oxidized with ethylene glycol thus playing a pivotal role within the conversion of ethylene glycol.

The reduced mechanism developed in the present work for describing the gasification of ethylene glycol comprises 48 species and 297 reactions. A comparison between the number of species and reactions of the detailed mechanism and the reduced mechanism is presented in Fig. 3. In total, a reduction grade of about $40 \%$ in the number of species and of $50 \%$ in the number of reactions is achieved. Usually, a reduction of species by about $40 \%$ will allow a reduction in computing time by about a factor of 5 for a two dimensional numerical simulation at typical gasifier conditions. 
Table 1. Reduction targets

\begin{tabular}{|l|l|l|l|l|l|}
\hline Mixture & Species & Target & $\begin{array}{l}\text { Pressure } \\
(\mathrm{bar})\end{array}$ & $\begin{array}{l}\text { Temperature } \\
(\mathrm{K})\end{array}$ & $\begin{array}{l}\text { Equivalence } \\
\text { ratio, } \varphi\end{array}$ \\
\hline $\begin{array}{l}\text { Ethylene } \\
\text { glycol/ air }\end{array}$ & $\begin{array}{l}\text { Ethylene } \\
\text { glycol }\end{array}$ & Laminar flame speed & 1 & 298 & 1 \\
\hline $\begin{array}{l}\text { Ethylene glycol } \\
\text { /air/ } \mathrm{N}_{2}\end{array}$ & $\begin{array}{l}\text { Ethylene } \\
\text { glycol }\end{array}$ & Ignition delay time & 1 & $\begin{array}{l}1100, \\
1500, \\
2000\end{array}$ & 1 \\
\hline $\begin{array}{l}\text { Ethylene glycol } \\
\text { /air/ } \mathrm{N}_{2}\end{array}$ & $\mathrm{H}_{2}$ & species concentration & 1 & $\begin{array}{l}1100, \\
1500, \\
2000\end{array}$ & $\begin{array}{l}1 \\
\text { (ethylene } \\
\text { glycol) }\end{array}$ \\
\hline
\end{tabular}

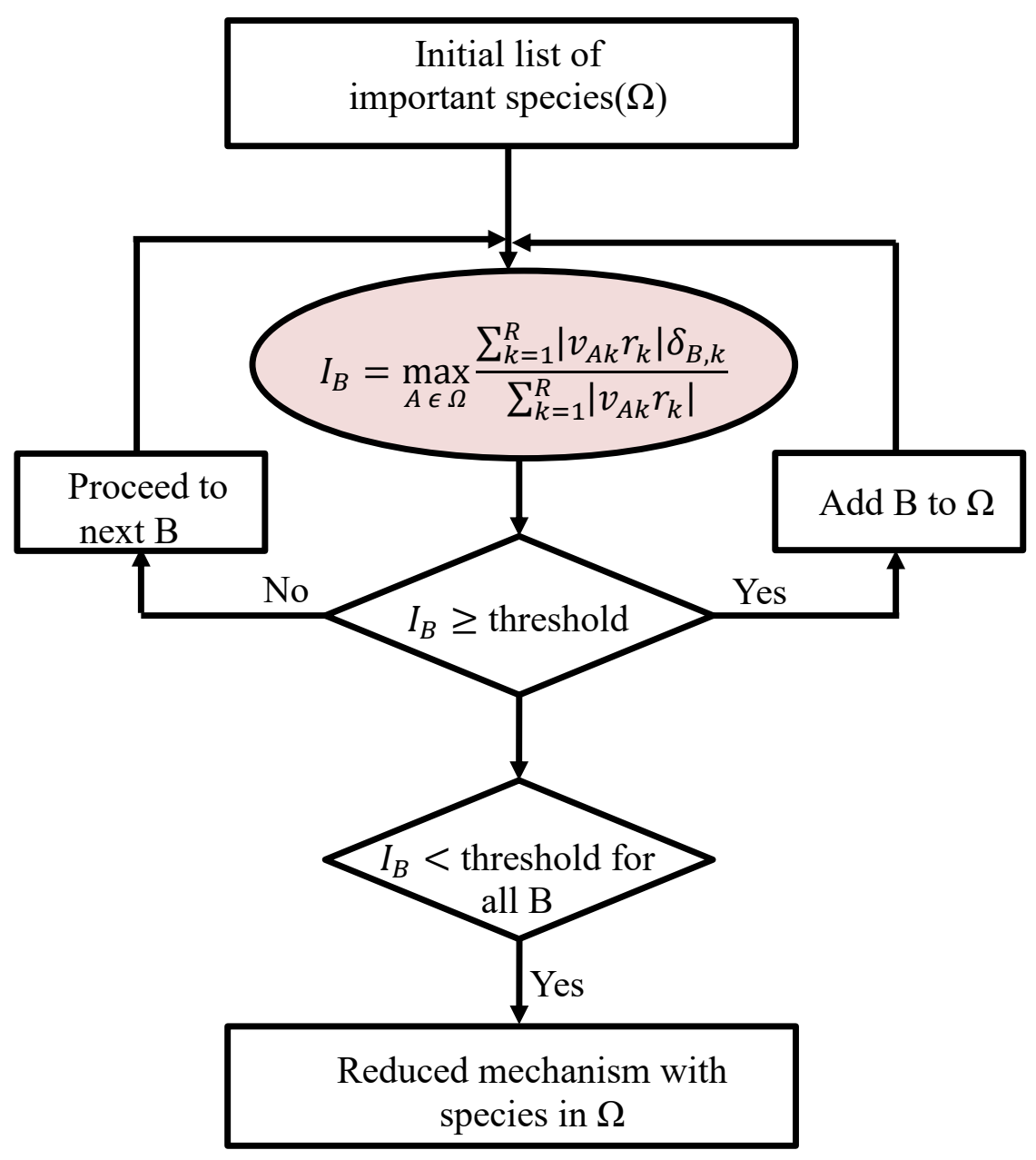

Figure 2. Protocol of the DRG mechanism reduction technique 


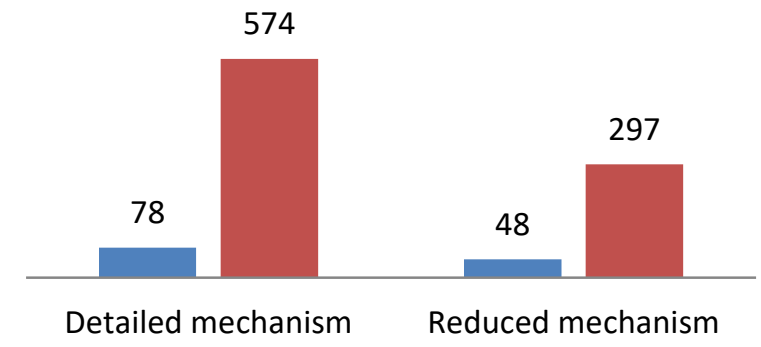

Figure 3. Comparison of the detailed and reduced mechanism with respect to number of species and reactions.

\section{METHODOLOGY AND VALIDATION APPROACH OF THE REDUCED REACTION MECHANISM}

\subsection{Laminar flame speed and ignition delay time computations}

The reduced mechanism developed using the methodology presented above is validated over a range of operating conditions and two different targets to ensure its similar performance to that of the detailed mechanism. For validation, published experimental data for ignition delay times and laminar flame speeds of ethylene glycol, acetaldehyde, methane and syngas are compared against numerically computed values using the reduced reaction mechanism. The species acetaldehyde and methane are formed as stable intermediates of ethylene glycol decomposition, as can be seen from the reaction pathway diagram in the study of Kathrotia et al. ${ }^{26}$ Syngas oxidation is important because in the gasification environment, syngas is brought to mix and combust together with ethylene glycol through a recirculation flow. ${ }^{18}$

The calorimetric bomb reactor module of the software Chemical Work Bench, ${ }^{29}$ with the assumptions of constant pressure and zero heat loss, is used for the numerical calculation of ignition delay times. The investigated conditions are: pressure range from 3.5 bar to 16.0 bar, temperature range from $800 \mathrm{~K}$ to $1800 \mathrm{~K}$, and equivalence ratio range from 0.5 to 2.0 .

The software package Cantera, ${ }^{32}$ with the assumption of a premix flat flame, is used to calculate the laminar flame speeds. Mesh points in the calculation were refined using the "slope" and "curve" settings of the Cantera ${ }^{32}$ flame calculation to obtain a converged solution according to the set tolerances. The investigated conditions are: pressure range from $1.0 \mathrm{bar}$ to $3.0 \mathrm{bar}$, temperature range from $298 \mathrm{~K}$ to $358 \mathrm{~K}$, and equivalence ratio range from 0.5 to 1.8 . 
A summary of the validation computations is presented in Table 2 (ignition delay times) and Table 3 (flame speeds). The comparison between the experimental data, the ones calculated using the detailed mechanism of Kathrotia et al. ${ }^{26}$ and those calculated using the reduced mechanism developed in the present work are presented in Figs. 5-10 in section 4.

Table 2. Summary of the ignition delay time computations

\begin{tabular}{llll}
\hline Species & $\begin{array}{l}\text { Pressure } \\
(\text { bar })\end{array}$ & $\begin{array}{l}\text { Temperature } \\
(\mathrm{K})\end{array}$ & $\begin{array}{l}\text { Fuel equivalence } \\
\text { ratio, } \varphi\end{array}$ \\
\hline acetaldehyde & $3.5-5$ & $1250-1800$ & $0.5,1.0,2.0$ \\
\hline methane & $3.5-50$ & $900-1700$ & 0.5 \\
\hline ethylene glycol & 16 & $800-1600$ & 1.0 \\
\hline $\begin{array}{l}\text { syngas } \\
50 \% \mathrm{CO}+50 \% \mathrm{H}_{2}\end{array}$ & 4 & $950-1425$ & 1.0 \\
\hline
\end{tabular}

Table 3. Summary of the laminar flame speed computations

\begin{tabular}{llll}
\hline Species & Pressure (bar) & Temperature $(\mathrm{K})$ & $\begin{array}{l}\text { Equivalence } \\
\text { ratio, } \varphi\end{array}$ \\
\hline acetaldehyde & 1.0 & $298-358$ & $0.6-1.8$ \\
\hline ethylene gylcol & 1.0 & 338 & $0.5-1.6$ \\
\hline methane & $1.0-3.0$ & 298 & $0.6-1.5$ \\
\hline
\end{tabular}

\subsection{CFD simulation}

The reduced reaction mechanism described in the previous section is used in an Euler-Euler CFD simulation to model the entrained flow gasification process of ethylene glycol as described in literature. $^{25}$ The radial species and temperature profiles calculated using the CFD simulation are used to further validate the mechanism. The CFD simulation is performed using the open source CFD tool OpenFOAM ${ }^{33}$ using a solver based on the reactingTwophaseEulerFoam solver ${ }^{31,34-35}$ from the OpenFOAM package. In the CFD simulation, the conservation equations for momentum, mass, and energy as given by Eqns. $2-5$ are numerically solved to obtain the flow field, species mass fractions, and temperature field inside the computational geometry. The results are given in Figs. 7-9.

\subsubsection{Governing equations}

The local thermo-chemical state of each phase $i$ is obtained by solving the momentum, mass and energy conservation equations, given in Eqns. 2-5.

The velocity fields of each phase are given by the momentum conservation equation: ${ }^{36}$ 


$$
\frac{\partial \rho_{i} \varepsilon_{i} U_{i}}{\partial t}+\nabla \cdot\left(\varepsilon_{i} \rho_{i} U_{i} U_{i}\right)+\nabla \cdot\left(\varepsilon_{i} \rho_{i} R_{i}\right)=-\varepsilon_{i} \nabla p+\varepsilon_{i} \rho_{i} g+M_{i} .
$$

The phase fractions $\varepsilon_{i}$, are obtained by using the continuity equation for each phase $i:^{36}$

$$
\frac{\partial \rho_{i} \varepsilon_{i}}{\partial t}+\nabla \cdot\left(\rho_{i} \varepsilon_{i} U_{i}\right)=\dot{m}_{i}
$$

The species mass fractions are obtained by solving the mass conservation equations ${ }^{37}$ for each of the species present in the mechanism:

$$
\frac{\partial \varepsilon_{g} \rho_{g} Y_{S}}{\partial t}+\nabla \cdot\left(\varepsilon_{g} \rho_{g} U_{g} Y_{S}\right)-\nabla \cdot\left(\varepsilon_{g} \rho_{g} D_{i, e f f} \nabla Y_{S}\right)=\dot{m}_{s} .
$$

The temperature fields are calculated using the energy conservation equation: ${ }^{37}$

$$
\frac{\partial \varepsilon_{i} \rho_{i} H_{i}}{\partial t}+\nabla .\left(\varepsilon_{i} \rho_{i} U_{i} H_{i}\right)-\nabla .\left(\varepsilon_{i} \rho_{i} k_{i, e f f} \nabla H_{i}\right)=\dot{h}_{i} .
$$

The source terms in the governing equations (Eqs. 2 - 5) describe the chemical and physical processes in the gasification environment. The source term for the momentum equation consists of interphase momentum transfer (drag) between the liquid and gas phases. The source terms in the continuity equations accounts for mass transfer and evaporation processes. Thermal radiation, interphase heat transfer and heat generation by chemical reactions contribute to the source term of the energy equation. The source terms of the species conservation equations are the production rates of the chemical species calculated using the reduced reaction mechanism. In the simulation, these processes are modeled using the sub models in the OpenFOAM package presented in Table 4.

Table 4. Sub models used for source terms in governing equations

\begin{tabular}{ll}
\hline Process & Sub model \\
\hline Turbulence & $\begin{array}{l}\text { RANS approach } \\
\text { Standard k-epsilon turbulence model }\end{array}$ \\
\hline Momentum transfer & Gidaspow drag model \\
\hline Heat and mass transfer & Clift correlation for $\mathrm{Nu}$ number $^{40}$ \\
\hline Evaporation & Spalding model \\
\hline Radiation & P1 radiation model \\
\hline Chemistry & $\begin{array}{l}\text { Reduced reaction mechanism for ethylene glycol } \\
\text { Partially stirred reactor (PaSR) turbulence } \\
\text { chemistry interaction model }\end{array}$ \\
\hline
\end{tabular}




\subsubsection{Model geometry}

The REGA gasifier operated at $\mathrm{KIT}^{25}$ consists of a ceramic tube of an internal diameter of $0.28 \mathrm{~m}$ and a height of $3.00 \mathrm{~m}$. Ethylene glycol and air are injected at the top center of the tube through a nozzle where it is ignited. ${ }^{25}$ The corresponding geometry and the computational domain for the CFD simulations are illustrated in Fig. 4. It is assumed that the flow field in the gasifier is axisymmetric. Therefore a two dimensional geometry is used for its calculation. The model considers only the $1000 \mathrm{~mm}$ downstream of the injection point. This simplification is made because the flame penetrates to approximately $600 \mathrm{~mm}$ downstream of the injection point and most of the fuel conversion takes place in the flame zone. Passing the flame, the gas compositions reach equilibrium values, depending on the axial temperature, which is observed to be uniform. ${ }^{18}$ It is assumed that no further significant variation of gas composition occurs downstream of the $1000 \mathrm{~mm}$ point.

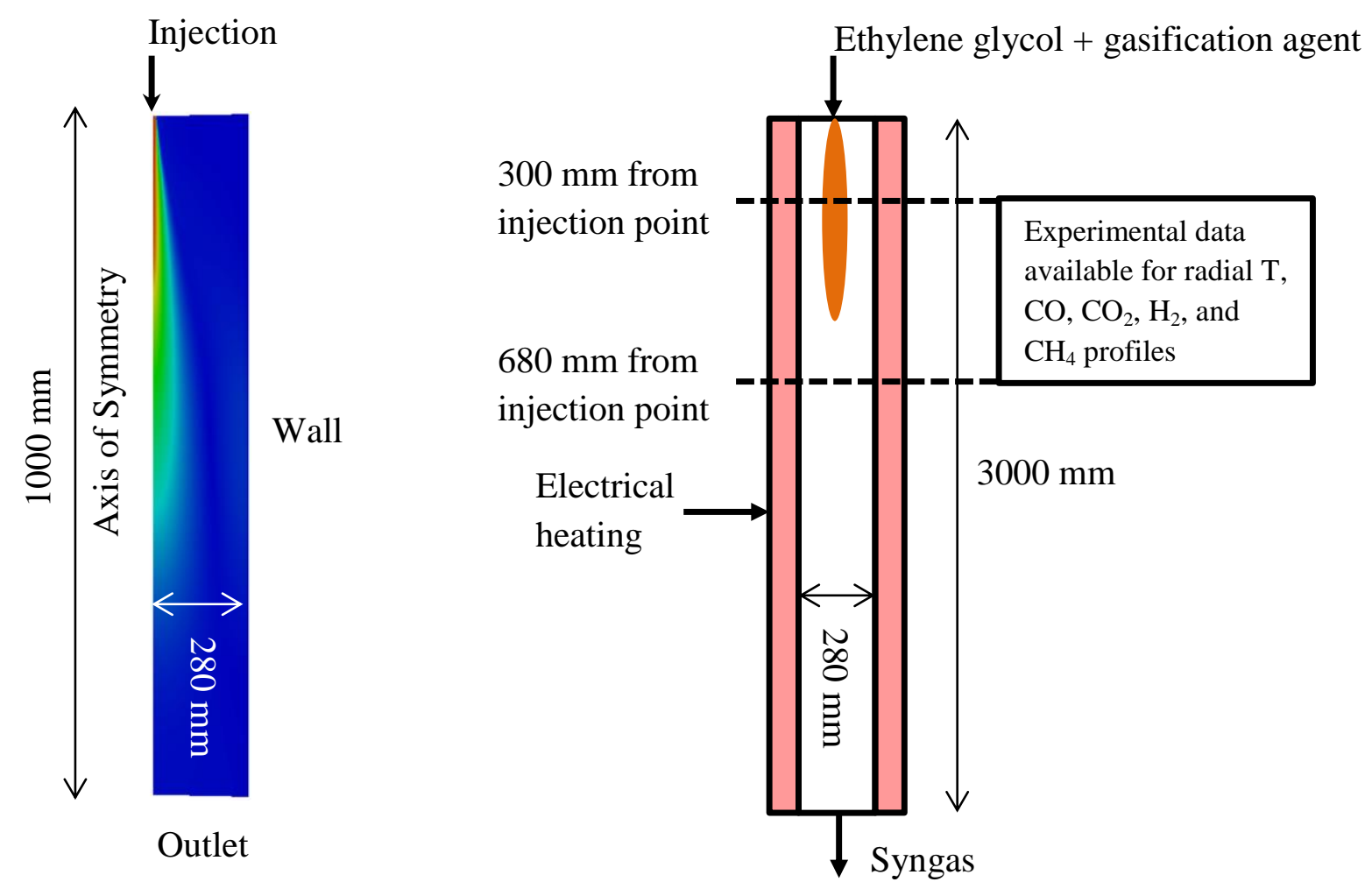

Figure 4. Model geometry and overview of the experimental set up of the REGA. ${ }^{25}$ 


\subsubsection{The numerical solution}

The simulations were performed using parallel computing, with $10 \mathrm{CPUs}$ at $2.5 \mathrm{GHz}$. With the reduced reaction mechanism, the time for a simulation to reach the steady state was approximately 14 days.

The initial and boundary conditions used for the simulations corresponding to the experimental conditions published in the study of Fleck et al. ${ }^{25}$ are presented in Table 5. The results of the CFD simulation are presented in section 4.1.2.

Table 5. Initial and boundary conditions of the REGA simulation

\begin{tabular}{|l|l|l|l|l|}
\hline & Velocity & Pressure & Temperature & $\begin{array}{l}\text { Species mass } \\
\text { fractions }\end{array}$ \\
\hline Inlet & \multicolumn{1}{|c|}{$125 \mathrm{~m} \mathrm{~s}^{-1}$} & $P_{\text {in }}=1 \mathrm{~atm}$ & $T_{\text {in, }, l}=300 \mathrm{~K}$ & $\mathrm{O}_{2}=0.516$ \\
$\mathrm{~N}_{2}=0.484$ \\
& & & & $\mathrm{EG}_{\text {liquid }}=1$ \\
\hline Wall & No slip condition & Zero gradient & Zero gradient & Zero gradient \\
\hline Outlet & Zero gradient & Zero gradient & Zero gradient & Zero gradient \\
\hline Initial condition & $(0,0,0)$ & 1 atm & $T_{g}=1473 \mathrm{~K}$ & $\mathrm{O}_{2}=0$ \\
& & & $T_{l}=300 \mathrm{~K}$ & $\mathrm{~N}_{2}=0.25$ \\
& & & $\mathrm{H}_{2}=0.015$ \\
& & & $\mathrm{CO}=0.25$ \\
& & & $\mathrm{CO}_{2}=0.245$ \\
& & & $\mathrm{H}_{2} \mathrm{O}=0.24$ \\
\hline
\end{tabular}

\subsubsection{Parameteric study}

The validated reduced reaction mechanism is used to perform a parameter study of the REGA gasifier, ${ }^{25}$ with the aim of investigating the effect of the operating conditions on the composition of the syngas produced. The investigated parameters are: Fuel pre-heat temperature, equivalence ratio, and the operating pressure of the gasifier. A series of CFD simulations are performed by varying each of these three factors while keeping the other two constant. A summary of the parameters is presented in Table 6. 
Table 6. Summary of the CFD simulations of the parameter study

\begin{tabular}{cccc}
\hline Simulation number & $\begin{array}{l}\text { Fuel preheat } \\
\text { temperature }(\mathrm{K})\end{array}$ & $\begin{array}{l}\text { Operating pressure } \\
(\mathrm{atm})\end{array}$ & $\begin{array}{l}\text { Equivalence ratio } \\
\text { phi }\end{array}$ \\
\hline Inflow temperature & & 1 & \\
\hline 1 & 300 & 1 & 2.12 \\
\hline 2 & 325 & 1 & 2.12 \\
\hline 3 & 350 & 1 & 2.12 \\
\hline 4 & 375 & 1 & 2.12 \\
\hline 5 & 400 & 1 & 2.12 \\
\hline 6 & 425 & & 2.12 \\
\hline Pressure & & 1 & 2.12 \\
\hline 1 & 300 & 2 & 2.12 \\
\hline 7 & 300 & 3 & 2.12 \\
\hline 8 & 300 & 4 & 2.12 \\
\hline 9 & 300 & 5 & 1.50 \\
\hline 10 & 300 & & 1.67 \\
\hline Equivalence ratio & & 1 & 1.80 \\
\hline 11 & 300 & 1 & 2.00 \\
\hline 12 & 300 & 1 & 2.12 \\
\hline 13 & 300 & 1 & \\
\hline 14 & 300 & 1 & \\
\hline 1 & 300 & & \\
\hline
\end{tabular}

\section{RESULTS AND DISCUSSION}

4.1 Validation of the reduced reaction mechanism

4.1.1 Ignition delay time and laminar flame speed computations

Figures 5 and 6 present the results of the ignition delay time and laminar flame speed computations of ethylene glycol, acetaldehyde, methane, and syngas, also showing the comparison between the detailed and the reduced mechanism. 


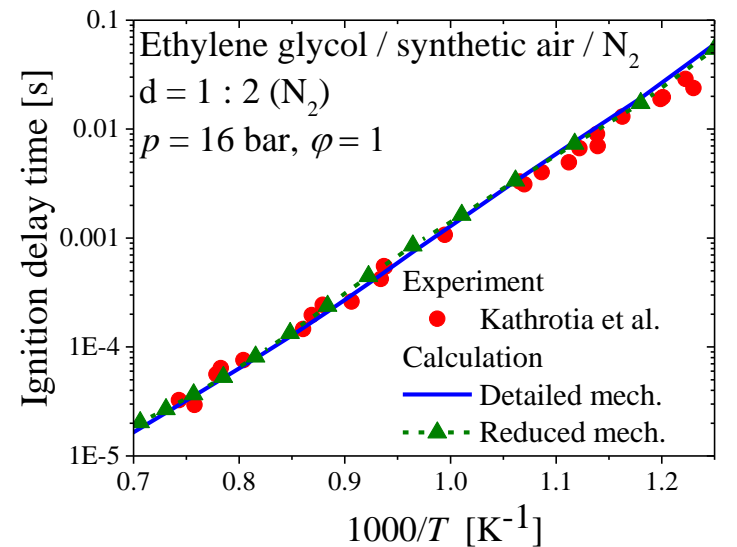

(a)

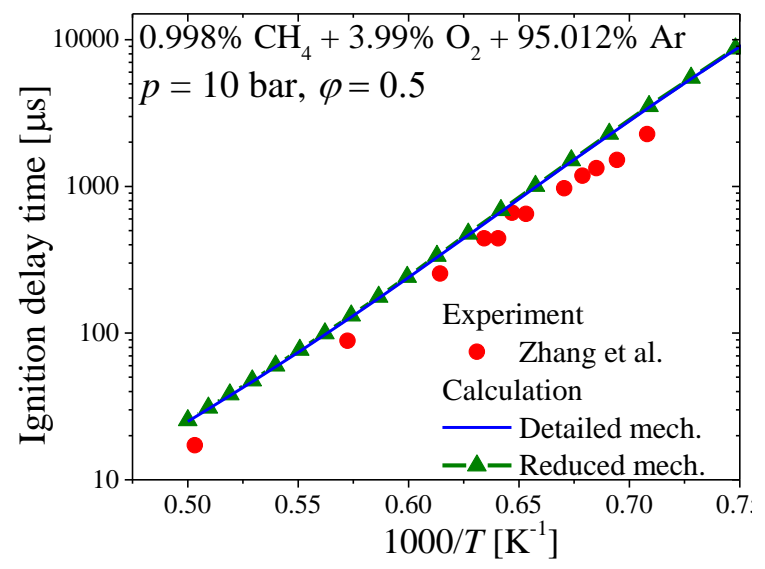

(b)

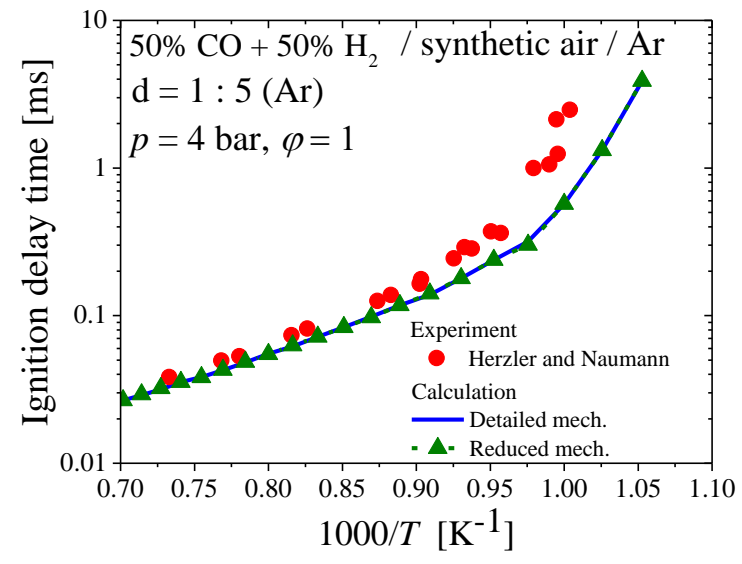

(c)

Figure 5. Calculated (curves; this work) and experimental (symbols; Kathrotia et al. ${ }^{26}$ Zhang et al., ${ }^{45}$ Herzler and Naumann ${ }^{46}$ ) ignition delay times of (a) ethylene glycol/air, (b) methane/air, and (c) syngas/air mixtures.

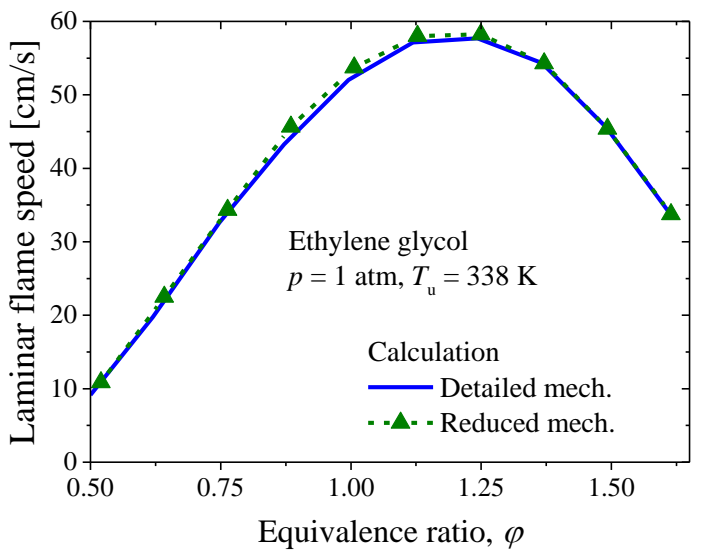

(a)

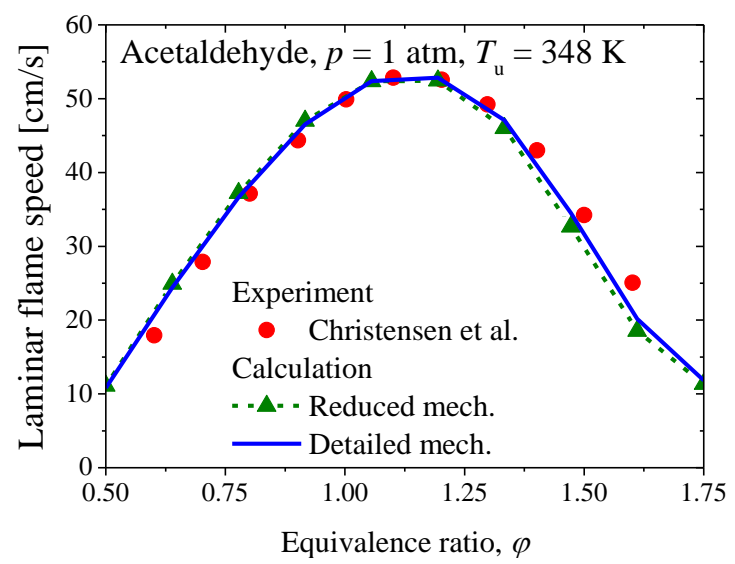

(b)

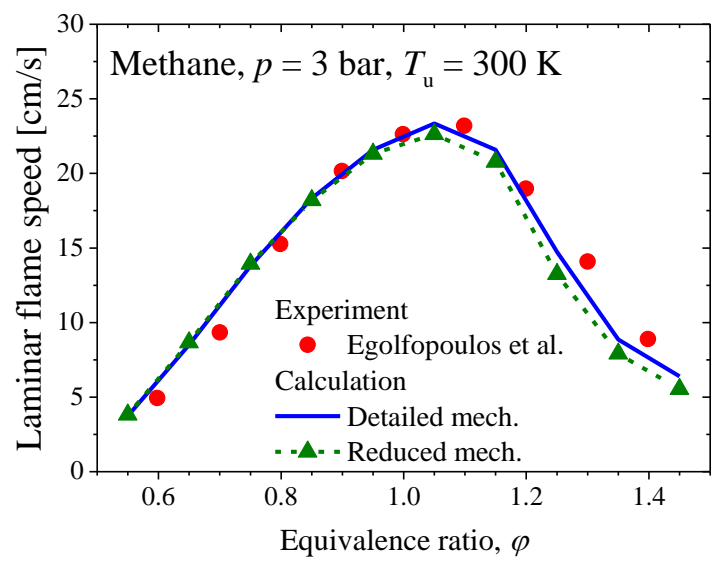

(c)

Figure 6. Calculated (curves; this work) and experimental (symbols; Christensen et al., ${ }^{47}$ Egolfopoulos et al ${ }^{48}$ ) laminar flame speeds of (a) ethylene glycol/air, (b) acetaldehyde/air, and (c) methane/air mixtures. 
The reduced mechanism has an excellent agreement with both the experimental data and the calculated ones by exploiting the detailed mechanism in predicting the ignition delay times of ethylene glycol (Fig. 5(a)) for temperatures between $800 \mathrm{~K}-1350 \mathrm{~K}$ and at a pressure of 16 bar. The methane $\left(\mathrm{CH}_{4}\right)$ ignition delay times are well predicted by the reduced mechanism (Fig. 5(b)). Figure 5(c) presents the comparison of measured and predicted ignition delay times for syngas consisting of $\mathrm{H}_{2}$ and $\mathrm{CO}$ in same percentage. The mixture was diluted 1:5 with Ar. The mechanism gives a good prediction of the ignition delay times for temperatures above approximately $1100 \mathrm{~K}$. The ignition delay times are under-predicted in the low temperature region by up to about a factor of 3 for temperature below about $1000 \mathrm{~K}$. It is interesting to note that the much longer reaction times in this temperature region are reflecting the importance of the $\mathrm{HO}_{2}$ sub model. The under prediction in the low temperature region can be expected because the base mechanism is a high temperature ethylene glycol mechanism. The temperature in the REGA is higher than $1400 \mathrm{~K}$, which indicated that only the high temperature chemistry is important for the REGA simulation.

Due to the lack of experimental data for ethylene glycol flame speeds, it is not possible to compare predicted data against experimental data. Therefore in Fig. 6(a), ethylene glycol flame speeds calculated using the reduced mechanism are compared against the values as obtained from calculations with the detailed reaction mechanism. Again, a very good agreement between the reduced mechanism and the detailed mechanism can be observed.

Also, laminar flame speed data of acetaldehyde $\left(\mathrm{CH}_{3} \mathrm{CHO}\right)$ a molecule that is a direct decomposition product of the oxidation of ethylene glycol, ${ }^{26}$ are well predicted by the reduced mechanism, both under fuel lean and fuel rich conditions as displayed in Fig. 6(b). Moreover, the calculations correctly predict the position of the maximum flame speed. The mechanism shows similar performance with respect to methane except a slight underprediction of the flame speed in the fuel rich region as shown in Fig. 6(c). The observed deviations between the reduced and detailed mechanism for the methane computations are considered as all right as methane itself was not selected as a specific target species within the mechanism reduction protocol. Note the observed deviations with respect to methane are not larger than $11 \%$. Thus, the reduced reaction model is considered to be capable for describing methane chemistry at these fuel rich conditions, too.

In all these computations, the reduced mechanism shows very good agreement with both the detailed mechanism and the experimental data, for different species and in a wide range of temperature, pressure, and fuel-air equivalence ratio as well as grade of dilution of the specific mixtures.

\subsubsection{Temperature Profiles and Species Profiles in CFD Simulations}

Figure 7 presents the calculated temperature profiles of the REGA gasifier, at distances of 300 $\mathrm{mm}$ and $680 \mathrm{~mm}$ downstream of the injection point. At $300 \mathrm{~mm}$ location, the radial temperature varies from about $1625 \mathrm{~K}$ at the wall region of the reactor to a maximum of $2000 \mathrm{~K}$ at the reactor 
axis. The temperature profile at the $600 \mathrm{~mm}$ location is nearly uniform, with only a slight variation $(50 \mathrm{~K})$ between the wall and the center. At both locations, the calculated profiles are in good agreement with the experimental data. In the study of Fleck at el. ${ }^{25}$ the equilibrium temperature profiles of the REGA were calculated using the assumption of water gas shift equilibrium. While their equilibrium profiles were in good agreement with the measured data for measurements outside the flame zone, the temperature variation was not well predicted by the equilibrium calculation in the flame zone. ${ }^{25}$

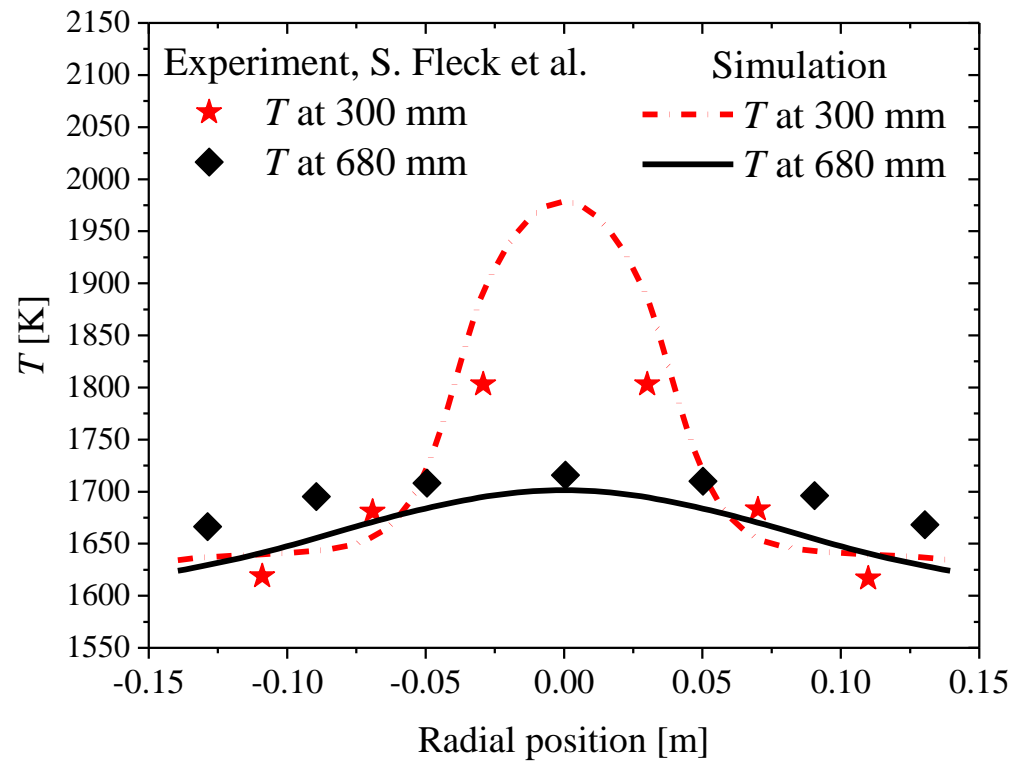

Figure 7. Calculated (curves; this work) and experimental (symbols; Fleck et al. ${ }^{25}$ ) radial temperature profiles at distances of $300 \mathrm{~mm}$ and $680 \mathrm{~mm}$ downstream of the injection point.

Figure 8 presents the calculated radial species profiles of $\mathrm{CO}, \mathrm{H}_{2}, \mathrm{CO}_{2}$, and $\mathrm{CH}_{4}$ using the CFD simulation of REGA for the conditions presented in table 5 at a distance of $300 \mathrm{~mm}$ downstream of the injection point; see Fig. 4. The experimental data (symbols) are obtained from the study of Fleck et al. ${ }^{25}$. The simulations are in good agreement with the experiment in the wall region of the reactor, in terms of predicting the concentration of some of the main products within the gasification of the pyrolysis oil surrogate, $\mathrm{CO}, \mathrm{H}_{2}$, and $\mathrm{CO}_{2}$. In the flame region, both the $\mathrm{CO}$ and $\mathrm{H}_{2}$ concentrations are underpredicted in the simulations, while the $\mathrm{CO}_{2}$ concentration is overpredicted. The simulations do not well predict the composition of the minor component methane $\left(\mathrm{CH}_{4}\right)$, which is underpredicted by about $0.5 \%$. This disagreement with respect to methane computations can also be seen in the methane laminar flame speed computations presented earlier (see Fig. 6(c)) suggesting the deviation is due to the methane sub mechanism in the reduced mechanism.

In Fig. 9, species profiles calculated for a distance of $680 \mathrm{~mm}$ downstream of the injection point are presented against the experimental data. All the major species concentrations show very good 
agreement with the experimental data while the concentration of the minor product methane is over predicted by the simulation, by about $0.5 \%$.

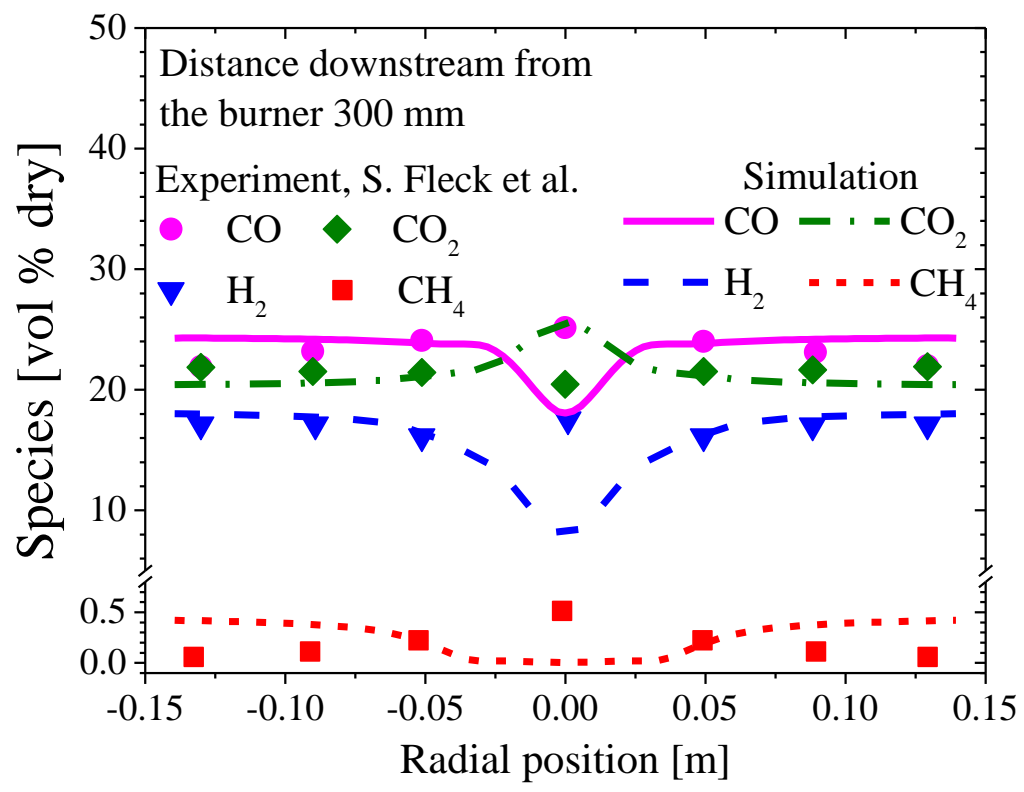

Figure 8. Calculated (curves; this work) and experimental (symbols; Fleck et al. ${ }^{25}$ ) radial species profiles of $\mathrm{CO}, \mathrm{H}_{2}, \mathrm{CO}_{2}$, and $\mathrm{CH}_{4}$ at a distance of $300 \mathrm{~mm}$ downstream of the injection point.

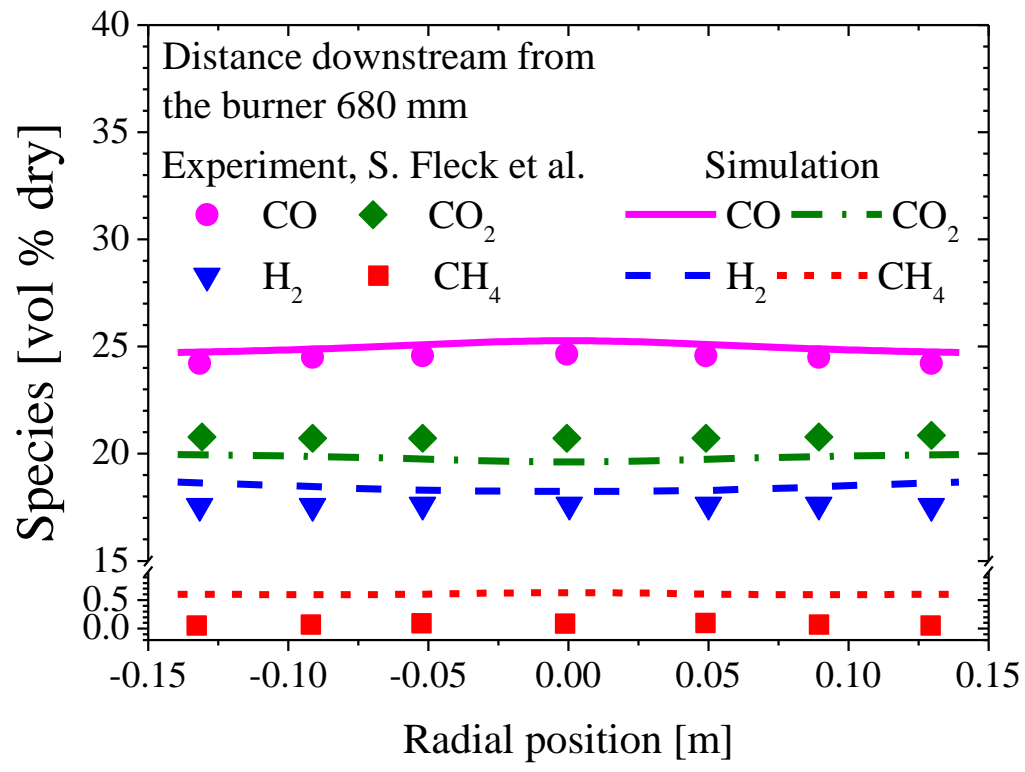

Figure 9. Calculated (curves; this work) and experimental (symbols; Fleck et al. $^{25}$ ) radial species profiles of $\mathrm{CO}, \mathrm{H}_{2}, \mathrm{CO}_{2}$, and $\mathrm{CH}_{4}$ at a distance of $680 \mathrm{~mm}$ downstream of the injection point. 
In summary, by considering all the validation calculations, it can be concluded that the developed reduced chemical kinetic mechanism can be used successfully to predict the gasification kinetics of ethylene glycol with respect to syngas production, within the specific temperature range, pressure, and fuel-air ratio.

\subsection{Effect of Operating Conditions on the Composition of Syngas}

This section presents the results of the CFD simulations of the parameter study of the REGA gasifier as described in section 3 .

\subsubsection{Effect of the fuel preheat temperature}

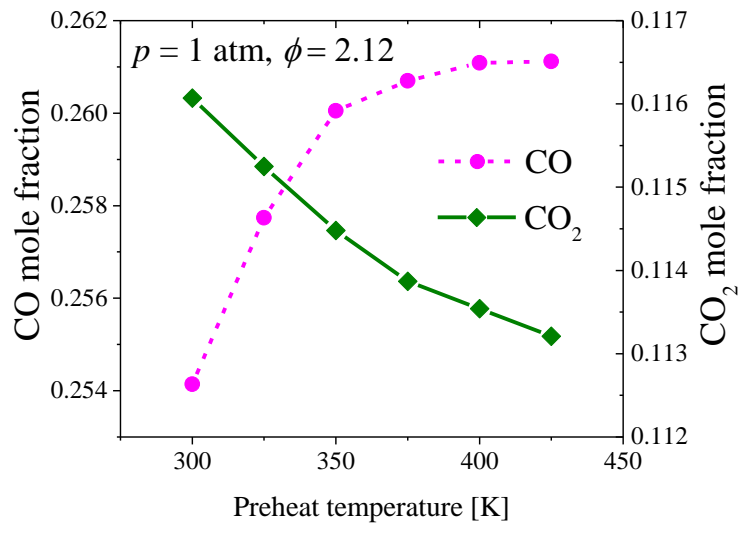

(a)

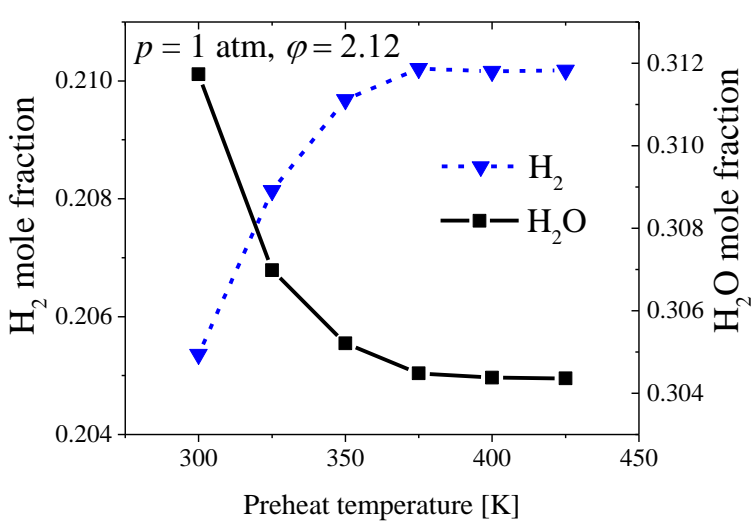

(b)

Figure 10. Calculated (reduced mechanism) exit mole fractions of (a) $\mathrm{CO}$ and $\mathrm{CO}_{2}$, (b) $\mathrm{H}_{2}$ and $\mathrm{H}_{2} \mathrm{O}$ vs. fuel preheat temperature at $p=1$ atm and $\phi=2.12$.

Figures 10 presents the variation of the syngas components $\mathrm{H}_{2}, \mathrm{H}_{2} \mathrm{O}, \mathrm{CO}$, and $\mathrm{CO}_{2}$ in tems of mole fractions at the exit against the preheat temperature of the liquid ethylene glycol. The lines in the figures connect the individual calculation results points (symbols) corresponding to the conditions given in Table 6 . The effect of increasing the preheat temperature, from $300 \mathrm{~K}$ to 450 $\mathrm{K}$, is a slight increase in $\mathrm{CO}$ and $\mathrm{H}_{2}$ mole fractions by less than $3 \%$ and a slight decrease in $\mathrm{CO}_{2}$ and $\mathrm{H}_{2} \mathrm{O}$ mole fractions by less than $2.5 \%$. This marginal variation can be explained by considering the evaporation of liquid ethylene glycol, the pyrolysis oil surrogate. With an increase of preheat temperature of liquid ethylene glycol, the amount of evaporated ethylene glycol emitted to the gas phase within the flame zone increases; this in turn increases values of the local equivalence ratio to the fuel rich direction, resulting in an increase of $\mathrm{CO}$ and $\mathrm{H}_{2}$. The variation cannot be observed after the preheat temperature has reached a certain value (about 375 $\mathrm{K})$ indicating that any further increase in the preheat temperature does not change significantly the fraction of evaporated liquid ethylene glycol within the flame zone. 


\subsubsection{Effect of the equivalence ratio}

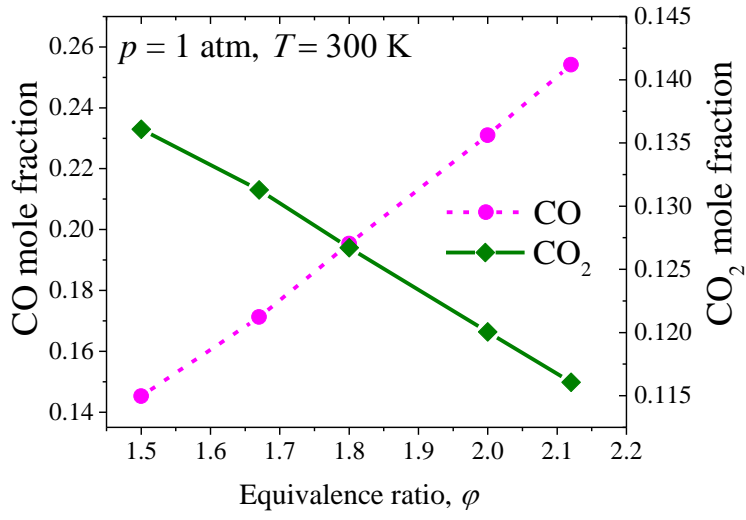

(a)

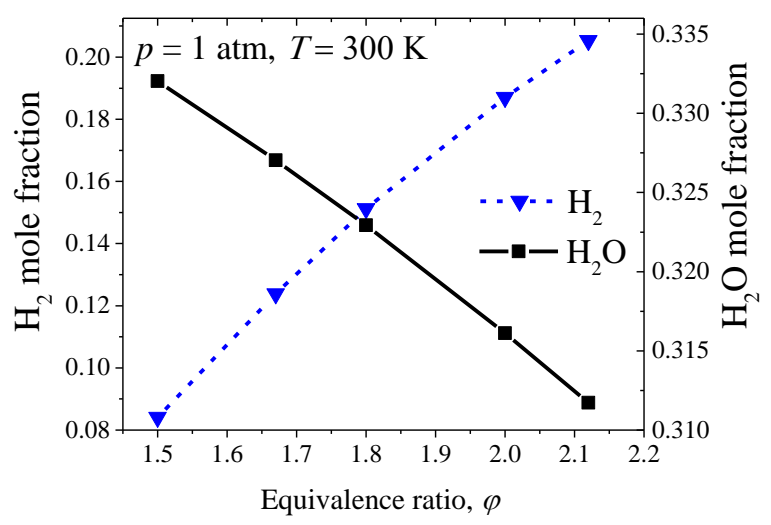

(b)

Figure 11. Calculated (reduced mechanism) exit mole fractions of (a) $\mathrm{CO}$ and $\mathrm{CO}_{2}$, (b) $\mathrm{H}_{2}$ and $\mathrm{H}_{2} \mathrm{O}$ vs. equivalence ratio at $p=1$ atm and a constant preheat temperature $T=300 \mathrm{~K}$.

The equivalence ratio has the strongest effect on the specific composition of the syngas. Figure 11 presents the variation of $\mathrm{CO}, \mathrm{H}_{2}, \mathrm{CO}_{2}$, and $\mathrm{H}_{2} \mathrm{O}$ in terms of mole fractions against the equivalence ratio $\varphi$. It can be seen that the variation is almost linear within the investigated equivalence ratio range. Similar results have been reported by an earlier study on the REGA gasifier using Euler-Lagrange simulations in the work of Rashidi et al. ${ }^{24}$ With the increase of equivalence ratio, the mole fractions of the combustible components $\left(\mathrm{CO}\right.$ and $\left.\mathrm{H}_{2}\right)$ increase, while the oxidation products $\mathrm{H}_{2} \mathrm{O}$ and $\mathrm{CO}_{2}$ decrease. This is because the oxygen amount in the inlet gas stream is increasingly insufficient to completely oxidize the fuel. In high temperature gasification processes such as entrained flow gasification, the operating equivalence ratios usually range from around $\varphi=1.5$ to $\varphi=2$. $^{49}$ In the REGA gasifier, the highest equivalence ratio used in the experiments is $2.3 .^{22}$ 


\subsubsection{Effect of the operating pressure}

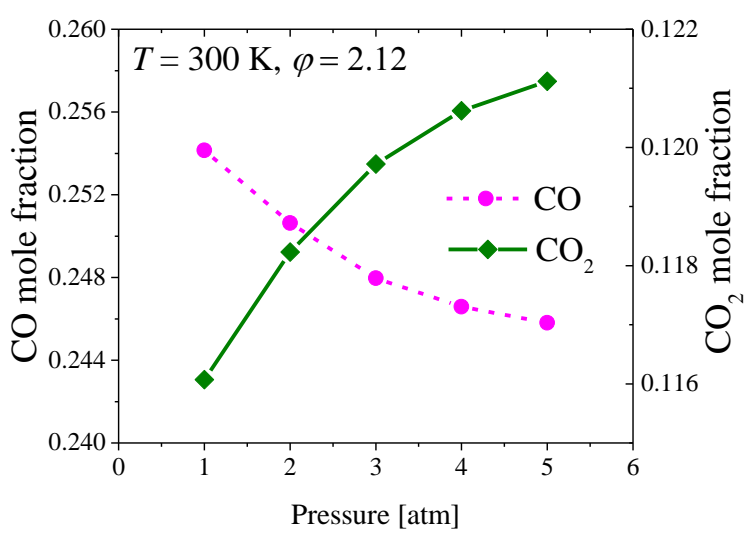

(a)

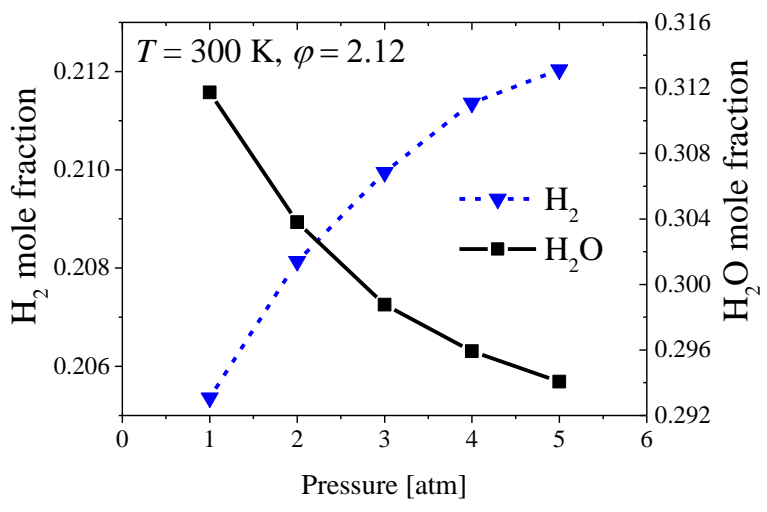

(b)

Figure 12. Calculated (reduced mechanism) exit mole fractions of (a) $\mathrm{CO}$ and $\mathrm{CO}_{2}$, (b) $\mathrm{H}_{2}$ and $\mathrm{H}_{2} \mathrm{O}$ vs. operating pressure at preheat temperature $T=300 \mathrm{~K}$ and $\phi=2.12$.

Figure 12 visualizes the effect of operating pressure on the syngas composition. The mole fractions of $\mathrm{CO}$ and $\mathrm{H}_{2} \mathrm{O}$ decrease with increasing pressure while those of $\mathrm{CO}_{2}$ and $\mathrm{H}_{2}$ increase. These results can be understood in terms of the equilibrium kinetics of the syngas at the gasifier's exit. The equilibrium relation between the syngas components can be approximated by the water gas shift reaction:

$$
\mathrm{CO}+\mathrm{H}_{2} \mathrm{O} \leftrightharpoons \mathrm{CO}_{2}+\mathrm{H}_{2}
$$

The equilibrium constant of the water gas shift reaction decreases with increasing temperature. ${ }^{50}$ In the simulations it has been observed that the temperature of the exit gas slightly decreases with the increase of pressure, therefore driving the equilibrium of reaction R1 to the right; this point can explain the observed variation of species concentrations seen in Fig. 12.

The values tend to become independent of pressure as the pressure increases further. The independence of the syngas composition from the operating pressure at pressures exceeding about 10 atm was also reported in another study with respect to the REGA. ${ }^{24}$

From the results of the simulations of the parameter study it can be observed that both the fuel preheat temperature and the operating pressure have a marginal influence on the composition of the syngas. The result of increasing the fuel preheat temperature is an increase of the mole fractions of hydrogen and carbon monoxide. With increasing pressure a slight increase in the hydrogen content and a slight decrease in the carbon monoxide content of the syngas is observed. However, in situations where the exit syngas will be subjected to a high pressure conversion 
processes such as the Fischer-Tropsch process, ${ }^{11}$ it would be advantageous to conduct the gasification process under higher pressures. According to the present simulations, the equivalence ratio had the strongest effect on the syngas composition, with an almost linear variation in the investigated equivalence ratio range.

\section{SUMMARY AND CONCLUSIONS}

In the present work, ethylene glycol has been selected as a surrogate fuel for pyrolysis oil. A reduced chemical kinetic reaction mechanism based on a detailed ethylene glycol chemical kinetic mechanism reported earlier ${ }^{26}$ was developed for ethylene glycol gasification using the socalled Directed Relation Graph method ${ }^{27-28}$ as implemented in the software Chemical Work Bench. ${ }^{29}$ The developed reduced reaction model was validated by computing ignition delay times and laminar flame speeds for species important for the decomposition of ethylene glycol over a wide range of parameters $(T, p, \varphi)$ as well as species profiles and temperature profiles in a two dimensional CFD simulation of an entrained gasifier and comparing the predicted results with experimental data available from literature. The results obtained in the present work by using the reduced reaction mechanism show very good agreement with the experimental data. Also, the validated mechanism was used in a parameter study of the REGA: A series of CFD simulations were performed by varying the fuel preheat temperature, the equivalence ratio, and the operating pressure, and the effect of these operating conditions on the exit gas composition of the gasifier was studied. As a summary, the newly formulated reduced reaction mechanism in combination with the single-component surrogate fuel will be a useful tool towards studying the gasification of a pyrolysis bio-oil more comprehensively.

\section{AUTHOR INFORMATION}

Corresponding Author

* E-mail: Niranjan.Fernando@dlr.de

Funding Sources

DLR-DAAD Research Fellowship No. 231, 2015.

\section{ACKNOWLEDGMENT}

N.F. thanks DAAD (German Academic Exchange Service) and DLR (German Aerospace Center) for providing the financial support for the research project through the DLR-DAAD Research Fellowship No. 231, 2015. 


\section{NOMENCLATURE}

$\begin{array}{ll}\varepsilon_{i} & \text { Volume fraction of the } i^{\text {th }} \text { phase } \\ \rho_{i} & \text { Density of the } i^{\text {th }} \text { phase }\left(\mathrm{kg} \mathrm{m}^{-3}\right) \\ v_{A k} & \text { Stoichiometric coefficient of species A in reaction } \mathrm{k} \\ g & \text { Gravitational acceleration }\left(\mathrm{m} \mathrm{s}^{-2}\right) \\ \dot{h}_{i} & \text { Energy source term in the } i^{\text {th }} \text { phase }\left(\mathrm{W} \mathrm{m}^{-3}\right) \\ k_{i, e f f} & \text { Effective thermal conductivity of the } i^{\text {th }} \text { phase }\left(\mathrm{W} \mathrm{m} \mathrm{K}^{-1}\right) \\ \dot{m}_{i} & \text { Mass source term in the } i^{\text {th }} \text { phase }\left(\mathrm{kg} \mathrm{m}^{-3} \mathrm{~s}^{-1}\right) \\ \dot{m}_{S} & \text { Rate of production of species } s\left(\mathrm{~kg} \mathrm{~m}^{-3} \mathrm{~s}^{-1}\right) \\ p & \text { Pressure }(\mathrm{Pa}) \\ r_{k} & \text { Reaction rate of the } k^{\text {th }} \text { reaction }\left(\mathrm{mol} \mathrm{s}^{-1}\right) \\ D_{i, e f f} & \text { Effective diffusivity of the } i^{\text {th }} \text { phase }\left(\mathrm{m}^{2} \mathrm{~s}^{-1}\right) \\ \mathrm{EG} & \text { Liquid ethylene glycol } \\ H_{i} & \text { Specific enthalpy of the } i^{\text {th }} \text { phase }\left(\mathrm{J} \mathrm{kg}^{-1}\right) \\ I_{A B} & \text { Species importance index } \\ M_{i} & \text { Interphase momentum transfer rate }\left(\mathrm{kg} \mathrm{m}^{-2} \mathrm{~s}^{-2}\right) \\ N u & \text { Nusselt number } \\ R_{i} & \text { Reynolds stress tensor of the } i^{\text {th }} \text { phase }\left(\mathrm{kg} \mathrm{m}^{-1} \mathrm{~s}^{-2}\right) \\ U_{i} & \text { Velocity of the } i^{\text {th }} \text { phase }\left(\mathrm{m} \mathrm{s}^{-1}\right) \\ Y_{S} & \text { Mass fraction of species s }\end{array}$

\section{REFERENCES}

(1) P. McKendry, "Energy production from biomass (part 2): conversion technologies," Bioresource Technology, vol. 83, no. 1, pp. 47-54, 2002.

(2) P. McKendry, "Energy production from biomass (part 3): gasification technologies," Bioresource Technology, vol. 83, no. 1, pp. 55-63, 2002.

(3) A. Molino, S. Chianese and D. Musmarra, "Biomass gasification technology: The state of the art overview," Journal of Energy Chemistry, vol. 25, no. 1, pp. 10-25, 2016.

(4) V. Dhyani and T. Bhaskar, "A comprehensive review on the pyrolysis of lignocellulosic biomass," Renewable Energy, vol. 129, no. Part B, pp. 695-716, 2018.

(5) W. Chen, K. Annamalai, R. James Ansley and M. Mirik, "Updraft fixed bed gasification of mesquite and juniper wood samples," Energy, vol. 41, no. 1, pp. 454-461, 2012.

(6) N. Fernando and M. Narayana, "A comprehensive two dimensional Computational Fluid Dynamics model for an updraft biomass gasifier," Renewable Energy, vol. 99, pp. 698-710, 
2016.

(7) R. Warnecke, "Gasification of biomass: comparison of fixed bed and fluidized bed gasifier," Biomass \& Bioenergy, vol. 18, pp. 489-497, 2000.

(8) "Fluidzed bed gasifiers," National energy technology laboratory, [Online]. Available: https://www.netl.doe.gov/research/coal/energysystems/gasification/gasifipedia/fluidizedbed. [Accessed 0304 2019].

(9) "Biofuels Academy," [Online]. Available: http://biofuelsacademy.org/index.html\%3Fp=204.html. [Accessed 2201 2019].

(10) "bioliq," [Online]. Available: https://www.bioliq.de/english/55.php. [Accessed 0512 2018].

(11) H. Mahmoudi, M. Mahmoudi, O. Doustdar, H. Jahangiri, A. Tsolakis, S. Gu and M. . L. Wyszynski, "A review of Fischer Tropsch synthesis process, mechanism, surface chemistry and catalyst formulation," Biofuels Engineering, no. 2, pp. 11-31, 2017.

(12) H. Liu, A. Elkamel, A. Lohi and M. Biglari, "Computational Fluid Dynamics Modeling of Biomass Gasification in Circulating Fluidized-Bed Reactor Using the Eulerian-Eulerian Approach," Ind. Eng. Chem. Res., vol. 52, no. 51, p. 18162-18174, 2013.

(13) B. Fortunato, G. Brunetti, S. M. Camporeale, M. Torresi and F. Fornarelli, "Thermodynamic model of a downdraft gasifier," Energy Conversion and Management, vol. 140, pp. 281-294, 2017.

(14) P. K. Senapati and S. Behera, "Experimental investigation on an entrained flow type biomass gasification system using coconut coir dust as powdery biomass feedstock," Bioresource Technology, vol. 117, pp. 99-106, 2012.

(15) C. Hanping, L. Bin, Y. Haiping, Y. Guolai and Z. Shihong, "Experimental Investigation of Biomass Gasification in a Fluidized Bed Reactor," Energy \& Fuels, vol. 22, no. 5, pp. 34933498, 2008.

(16) V. Kirsanovs, D. Blumberga, I. Veidenbergs, C. Rochas, E. Vigants and G. Vigants, "Experimental investigation of downdraft gasifier at various conditions," Energy Procedia, vol. 128, pp. 332-338, 2017.

(17) A. Z. Mendiburu, J. A. Carvalho Jr. and C. J. R. Coronado, "Thermochemical equilibrium modeling of biomass downdraft gasifier: Stoichiometric models," Energy, vol. 66, pp. 189201, 2014.

(18) M. Mancini, M. Alberti, M. Dammann, U. Santo, G. Eckel, T. Kolb and R. Weber, 
"Entrained flow gasification. Part 2: Mathematical modeling of the gasifier using RANS method," Fuel, vol. 225, pp. 596-611, 2018.

(19) G. Eckel, P. Le Clercq, T. Kathrotia, A. Saenger, S. Fleck, M. Mancini, T. Kolb and M. Aigner, "Entrained flow gasification. Part 3: Insight into the injector near-field by Large Eddy Simulation with detailed chemistry," Fuel, vol. 223, pp. 164-178, 2018.

(20) N. Slavinskaya and M. Braun-Unkhoff, "Reduced Reaction Mechanisms for Methane and Syngas Combustion in Gas Turbines," Journal of Engineering for Gas Turbines and Power, vol. 130, no. 2, 2008.

(21) C. A. Mullen and A. A. Boateng, "Chemical Composition of Bio-oils Produced by Fast Pyrolysis of Two Energy Crops," Energy \& Fuels, vol. 22, no. 3, pp. 2104-2109, 2008.

(22) T. Kolb, T. Jakobs and N. Zarzalis, "Syngas from biomass-based slurry entrained-flow gasification," in 10th Conference on Energy for a Clean Environment, Lisbon, Portugal, 710 July, 2009.

(23) S. Hafner, A. Rashidi, G. Baldea and U. Riedel, "A detailed chemical kinetic model of hightemperature ethylene glycol gasification," Combustion Therory and Modelling, vol. 15, no. 4, pp. 517-535, 2011.

(24) A. Rashidi, CFD Simulation of Biomass Gasification Using Detailed Chemistry, PhD dissertation, Naturwissenschaftlich-Mathematischen Gesamtfakultät, Ruprecht-KarlsUniversität, Heidelberg., 2011.

(25) S. Fleck, U. Santo, C. Hotz, T. Jakobs, G. Eckel, M. Mancini, R. Weber and T. Kolb, "Entrained flow gasification Part 1: Gasification of glycol in an atmospheric-pressure experimental rig," Fuel, vol. 217, pp. 306-319, 2018.

(26) T. Kathrotia, C. Naumann, P. Oßwald, M. Köhler and U. Riedel, "Kinetics of Ethylene Glycol: The first validated reaction scheme and first measurements of ignition delay times and speciation data," Combustion and Flame, vol. 179, pp. 172-184, 2017.

(27) T. Lu and C. K. Law, "A directed relation graph method for mechanism reduction," Proceedings of the Combustion Institute, vol. 30, pp. 1333-1341, 2005.

(28) A. V. Lebedev, M. V. Okun, V. A. Chorkov, P. M. Tokar and M. Strelkova, "Systematic procedure for reduction of kinetic mechanisms of complex chemical processes and its software implementation," Journal of Mathematical Chemistry, vol. 51, no. 1, pp. 73-107, 2013.

(29) "Chemical workbench," Kintech Laboratory, [Online]. Available: 
http://www.kintechlab.com/products/chemical-workbench/. [Accessed 0512 2018].

(30) N. Fernando, T. Kathrotia, Q. Fradet, M. Braun-Unkhoff and U. Riedel, "The oxidation of ethylene glycol - a pyrolysis oil surrogate," in Proc. 26th European Biomass Conference and Exhibition, Copenhagen, Denmark, 14 - 18 May 2018.

(31) Q. Fradet, M. Braun-Unkhoff and U. Riedel, "A Sectional Approach for the Entrained-Flow Gasification of Slurry Fuels," Energy \& Fuels, vol. 32, no. 12, p. 12532-12544, 2018.

(32) "Cantera," [Online]. Available: https://cantera.org/. [Accessed 0512 2018].

(33) "OpenFOAM," [Online]. Available: https://openfoam.org/. [Accessed 0512 2018].

(34) "OpenFOAM user guide," [Online]. Available: https://www.openfoam.com/documentation/user-guide/. [Accessed 0512 2018].

(35) P. P. Thummala, "Description of reactingTwoPhaseEulerFoam solver with a focus on mass transfer modeling terms," in Proceedings of CFD with OpenSource Software, 2016, Edited by Nilsson. H, http://dx.doi.org/10.17196/OS_CFD\#YEAR_2016.

(36) H. Rusche, Computational fluid dynamics of dispersed two-phase flows at high phase fractions, London: Imperial College of Science, Technology \& Medicine, Department of Mechanical Engineering, December 2002.

(37) D. Cappelli, "A detailed description of reactingTwoPhaseEulerFoam, focusing on the links between mass and heat transfer at the interface," in Proceedings of CFD with OpenSource Software, 2018, Edited by Nilsson H. http://dx.doi.org/10.17196/OS_CFD\#YEAR_2018.

(38) H. K. Versteeg and W. Malalasekera, An Introduction to Computational Fluid Dynamics: The Finite Volume Method, Harlow, England: Pearson Education Limited, 2007.

(39) T. Engen, CFD analysis of gas-particle flow in a scaled circulating fluidized bed, Stavanger: Faculty of Sicence and Technology, University of Stavanger, 2016.

(40) R. Clift, J. Grace and M. E. Weber, Bubbles, Drops, and Particles, Mineola, NY: Dover Civil and Mechanical Engineering Series, Dover Publications, 2005.

(41) D. B. Spalding, "The combustion of liquid fuels," Symposium (International) on Combustion, vol. 4, no. 1, pp. 847-864, 1953.

(42) P. Cheng, "Two-dimensional radiating gas flow by a moment method," AIAA Journal, vol. 2, no. 9, pp. 1662-1664, 1964. 
(43) S. Haider, K. M. Pang, A. Ivarsson and J. Schramm, "Combustion and radiation modeling of laminar premixed flames using OpenFOAM: A numerical investigation of radiative heat transfer in the RADIADE project," in CIMAC Congress 2013 Conseil International des Machines a Combustion. (CIMAC Paper; No. 274), 2013.

(44) M. T. Lewandowski and J. Pozorski, "Assessment of turbulence-chemistry interaction models in the computation of turbulent non-premixed flames," Journal of Physics: Conference Series, vol. 760, 012015.

(45) Y. Zhang, Z. Huang, L. Wei, J. Zhang and C. K. Law, "Experimental and modeling study on ignition delays of lean mixtures of methane, hydrogen, oxygen, and argon at elevated pressures," Combustion and Flame, vol. 159, pp. 918-931, 2012.

(46) J. Herzler and C. Naumann, "Shock Tube Study of the Ignition of Lean CO/H2 Fuel Blends at Intermediate Temperatures and High Pressure," Combustion Science and Technology, vol. 180, no. 10-11, pp. 2015-2028, 2008.

(47) M. Christensen, M. T. Abebe, E. J. K. Nilsson and A. A. Konnov, "Kinetics of premixed acetaldehyde+air flames," Proceedings of the Combustion Institute, vol. 35, no. 1, pp. 499$506,2015$.

(48) F. N. Egolfopoulos, P. Cho and C. K. Law, "Laminar Flame Speeds of Methane-Air Under Reduced and Elevated Pressures," Combustion and Flame, vol. 76, no. 3-4, pp. 375-391, 1989.

(49) W. Jangsawang, K. Laohalidanond and S. Kerdsuwan, "Optimum Equivalence Ratio of Biomass Gasification Process Based on Thermodynamic Equilibrium Model," Energy Procedia, vol. 79, pp. 520-527, 2015.

(50) C. A. Callaghan, Kinetics and Catalysis of the Water-Gas-Shift Reaction: A Microkinetic and Graph Theoretic Approach, PhD dissertation, Department of Chemical Engineering, WORCESTER POLYTECHNIC INSTITUTE, Worcester, United States, 2006. 